TITLE:

\title{
Preparation of fibrous cellulose by enzymatic polymerization using cross-linked mutant endoglucanase II.
}

\section{AUTHOR(S):}

Nakamura, Itsuko; Makino, Akira; Horikawa, Yoshiki; Sugiyama, Junji; Ohmae, Masashi; Kimura, Shunsaku

\section{CITATION:}

Nakamura, Itsuko ...[et al]. Preparation of fibrous cellulose by enzymatic polymerization using cross-linked mutant endoglucanase II.. Chemical communications 2011, 47(36): 10127-10129

\section{ISSUE DATE:}

2011-08-09

URL:

http://hdl.handle.net/2433/158959

\section{RIGHT:}

(C) Royal Society of Chemistry 2011.; This is not the published version. Please cite only the published version.; この論文は出版社版でありませ ん。引用の際には出版社版をご確認ご利用ください。 


\title{
Preparation of fibrous cellulose by enzymatic polymerization using cross-linked mutant endoglucanase $\mathrm{II} \uparrow$
}

\author{
Itsuko nakamura, ${ }^{a}$ Akira Makino, ${ }^{a}$ Yoshiki Horikawa, ${ }^{b}$ Junji Sugiyama, ${ }^{b}$ Masashi Ohmae ${ }^{a}$ and Shunsaku \\ Kimura ${ }^{* a}$
}

\author{
5 Received (in XXX, XXX) Xth XXXXXXXXX 2011, Accepted Xth XXXXXXXXX 2011 \\ DOI: 10.1039/b000000x
}

A cross-linked mutant endoglucanase II was prepared for enzymatic polymerization to cellulose. The cross-linked enzyme was composed of three mutant enzymes showing ${ }_{10}$ polymerization activity. A characteristic point of the polymerization with this cross-linked enzyme was formation of cellulose fibriles in contrast to plate-like crystals obtained by using a free enzyme.

Cellulose is the most abundant polysaccharide on the earth. ${ }_{15}$ In nature, cellulose is biosynthesized by cellulose synthase in land plants, algae, and microorganisms using uridin-5'diphospho (UDP)-glucose as substrate. ${ }^{1}$ Cellulose synthase is classified as glycosyltransferase, and forms a complex named terminal complex (TC). ${ }^{2}$ One TC subunit is considered to be 20 composed of $3-10$ cellulose synthases. ${ }^{3}$ And these single TC subunits are arranged in characteristic shapes depending on their origins such as a linear type or a cyclic type (rosette) with single or multiple rows. ${ }^{4}$ Moreover, discriminative cellulase complex with enormously high molecular weight 25 was found in some cellulolytic anaerobic bacteria. This macromolecular complex is named as cellulosome ${ }^{5}$ and shows tremendously higher hydrolysis activity comparing with cellulase (1-2 order) because of multi-site interaction of the cellulosome and a substrate due to proximity of multiple 30 enzymes. $^{6}$

The morphology of biosynthesized cellulose by these cellulose synthase is microfibril. The molecular packing in crystals and the crystalline form are considered to be determined by the spatial arrangements of the enzymes in TCs.

35 The size of microfibril is decided by the configuration of cellulose synthase, and larger TC is known to produce larger width microfibrils. ${ }^{7}$ In terms of crystalline form, linear type TCs mainly synthesize triclinic crystalline cellulose, whilst the rosette type TCs produce largely monoclinic crystalline

${ }^{a}$ Department of Material Chemistry, Graduate School of Engineering, Kyoto University, Kyoto-Daigaku-Katsura, Nishikyo-ku, Kyoto 615-8510, Japan. Fax: +81 75-383-2401; Tel: +81 75-383-2400; E-mail:

shun@scl.kyoto-u.ac.jp

${ }^{b}$ Research Institute for Sustainable Humanosphere (RISH), Kyoto

University, Gokasho, Uji, Kyoto 611-0011 Japan.

$\dagger$ Electronic Supplementary Information (ESI) available: Experimental details of synthesis and characterization. Result of SDS-PAGE. Elution pattern of cross-linked EGII ${ }_{\text {core2H }}$. See DOI: 10.1039/b000000x/
40 cellulose. ${ }^{8}$ On the other hand, in the case of in vitro cellulose syntheses, the observed morphologies are mostly spherical and lamellar. ${ }^{9}$ Recently, productions of fibrous cellulose or crystalline cellulose were reported. ${ }^{10}$ However, they were synthesized from wood fiber or switchgrass by enzymatic 45 hydorolysis.

We have been studying on the properties of synthetic cellulose obtained by enzymatic polymerization ${ }^{11}$ using the mutant endoglucanase II (EGII) from filamentous fungi Trichoderma viride composed of only catalytic core domain. ${ }^{12}$ 50 It is reported that the increase of the number of the catalytic core domain in mutant EGII from one to two, both hydrolysis and polymerization activities per a catalytic core domain is increased. ${ }^{12 \mathrm{~b}}$ Moreover, the crystallinity of synthetic cellulose became higher by the increase of the number of the catalytic 55 core domain. ${ }^{12 \mathrm{~b}}$ Therefore, the coexistance of the catalytic core domains in close proximity seems to be a key factor for the activity of enzymatic polymerzation and the morphology of the product by the in vitro synthesis. It is thus expected that the morphology of synthetic cellulose can be controlled by the 60 arrangement of the catalytic core domains in the polymerization system, which is designed in resemblance to the in vivo sythesis of cellulose by cellulose synthase complex.

In the present study, mutant EGIIs were cross-linked to assemble, and the enzymatic polymerization to cellulose using ${ }_{65}$ the cross-linked EGII as a catalyst was investigated. The cross-linking molecule used is bisNTA which has two nitrilotriacetic acid (NTA) moieties on both terminals of

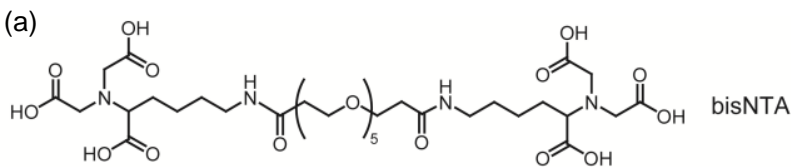

(b)

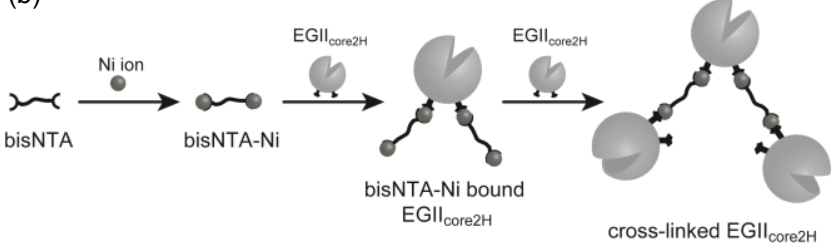

Fig. 1 (a) Chemical structure of bisNTA. (b) Schematic illustration of cross-linking of EGII core2H. $_{\text {. }}$ 
polyethylene oxide (PEO) (Fig. 1a). The NTA moiety is one of the most utilized ligand which is known to interact with oligo histidine residues (His-tag) through transition metal ion such as Ni. ${ }^{13}$ BisNTA was synthesized by conventional 5 organic chemical reactions and confirmed by ${ }^{1} \mathrm{H}$ NMR. Mutant EGII used for cross-linking is EGII $_{\text {core2H }}$ which is composed of two sequentially aligned catalytic core domains with two His-tags (hexameric histidine residues) on both chain terminals. Because of these two His-tags, one EGII core2H $_{2}$ 10 is able to bind to two other $\mathrm{EGII}_{\text {core } 2 \mathrm{H}} \mathrm{S}$. $\mathrm{EGII}_{\mathrm{core} 2 \mathrm{H}}$ was obtained as a secreted protein from the transformed yeast cell bearing plasmid encoding EGII $_{\text {core } 2 \mathrm{H}}$ and purified by a metal immobilized affinity chromatography (Ni-NTA agarose beads) and a gel-permeation chromatography (Sephacryl S15 200) as described before. ${ }^{12 b}$ Both molecular weight and purity of the purified EGII $\mathrm{core}_{\mathrm{H}}$ were confirmed by SDS-PAGE.

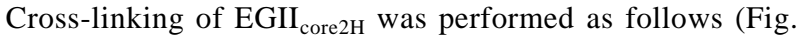
1b). First, bis-NTA was chelated with Ni ion (bisNTA-Ni). Then, an excess amount of bisNTA-Ni was incubated with ${ }_{20}$ EGII $_{\text {core2H }}$ to obtain the bisNTA-Ni-bound EGII ${ }_{\text {core2H }}$ in Fig. 1b. Another fresh $\mathrm{EGII}_{\text {core2H }}$ was added to bind to the free $\mathrm{Ni}$ moiety of the bisNTA-Ni-bound EGII ${ }_{\text {core2H }}$ to yield the crosslinked $\mathrm{EGII}_{\text {core2H }}$ in Fig. 1b. The obtained products were analyzed by gel-permeation chromatography (Sepahcryl S25 200). In the elution pattern, a broad peak with elution volume from 30 to $40 \mathrm{ml}$ was observed in advance of the peak of the free EGII $_{\text {core2H }}$ (Fig. 2, a and b). These fractions showed absorption at $395 \mathrm{~nm}$ due to the presence of $\mathrm{Ni}$ ions, supporting formation of the cross-linked $\mathrm{EGII}_{\mathrm{core} 2 \mathrm{H}}$ by the 30 bisNTA-Ni molecules. In comparison with the elution pattern of catalase from bovine liver (Fig. 2c, molecular weight is 232 $\mathrm{kDa}),{ }^{14}$ the cross-linked $\mathrm{EGII}_{\mathrm{core} 2 \mathrm{H}}$ is considered to be composed of at least three molecules of EGII $_{\text {core2H }}$ (the molecular weight of $\mathrm{EGII}_{\mathrm{core} 2 \mathrm{H}}$ is $72.3 \mathrm{kDa}$ ). We repeated the 35 cross-linking reactions to confirm the major product of the cross-linked EGII $_{\text {core2H }}$ composed of three molecules of EGII $_{\text {core2H }}$ (see supporting information). The fractions which eluted from 30 to $40 \mathrm{~mL}$ of elution volume were collected to eliminate non-cross-linked EGII $_{\text {core2H }}$ and concentrated by 40 ultrafiltration. We used the partially purified cross-linked $\mathrm{EGII}_{\text {core2H }}$ for the following polymerization experiments.

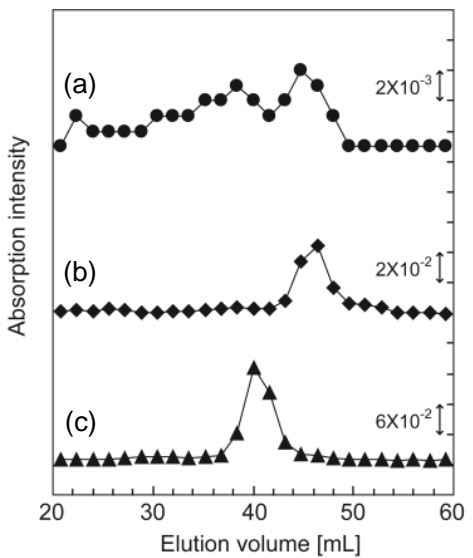

Fig. 2 Elution Pattern of gel-permeation chromatography of (a) crosslinked $\mathrm{EGII}_{\mathrm{core} 2 \mathrm{H}},(\mathrm{b})$ non-cross-linked $\mathrm{EGII}_{\mathrm{core} 2 \mathrm{H}}$ and (c) catalase from bovine liver.
Subsequently, enzymatic polymerization of $\beta$-cellobiosyl fluoride to synthesize cellulose was carried out in the acetonitrile/acetate buffer $(50 \mathrm{mM}, \mathrm{pH} 5.0)=3 / 1 \mathrm{v} / \mathrm{v}$ mixture 45 solution using the cross-linked EGII ${ }_{\text {core } 2 \mathrm{H}}$ as a catalyst. After $0.5 \mathrm{~h}$, white precipitation was suddenly observed in the reaction solution, whose appearance was different from the case of the artificial cellulose synthesis using the mutant EGII as a catalyst, where the polymerization solution became turbid 50 gradually with time. ${ }^{12 \mathrm{a}, \mathrm{b}}$ The different precipitation behaviors between the two enzymes suggest different crystalization of the products.

After $48 \mathrm{~h}$, the precipitates were collected, and the soluble fraction in acetonitrile was analyzed by MALDI-TOF MS. In ${ }_{55}$ Fig. 3, peaks equivalent to 8,10 and 12 glucose units of cellulose with $\mathrm{Na}$ adducts with an equal interval of $\mathrm{m} / \mathrm{z} 324$ which corresponds to molecular weight of a cellobiose unit are observed (Fig. 3), indicating formation of cellulose. Even though the observed peaks were up to 12 glucose units, 60 synthetic celluloses of higher molecular weight should be produced as an insoluble fraction in acetonitrile. Notably, the products are composed of glucosyl units of even numbers, which is reasonable for polymerization with using a disacchride monomer. However, enzymatic polymerization ${ }_{65}$ generally yielded cellulose of glycosyl units of odd numbers as well as even numbers, since the products were subjected to in situ hydrolysis by the enzyme as previously reported. ${ }^{12 a, 15}$ In the present case, the synthesized cellulose was not ameanable to hydrolysis probably due to the fast

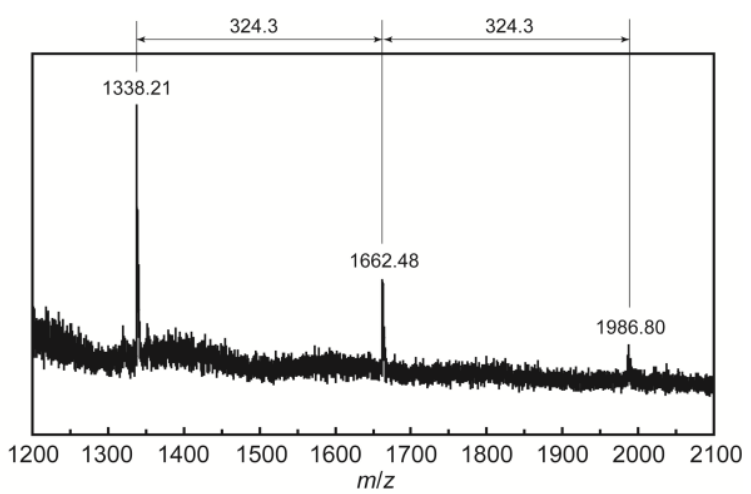

Fig. 3 MALDI-TOF MS spectrum of the product using cross-linked EGII $_{\text {core2H }}$

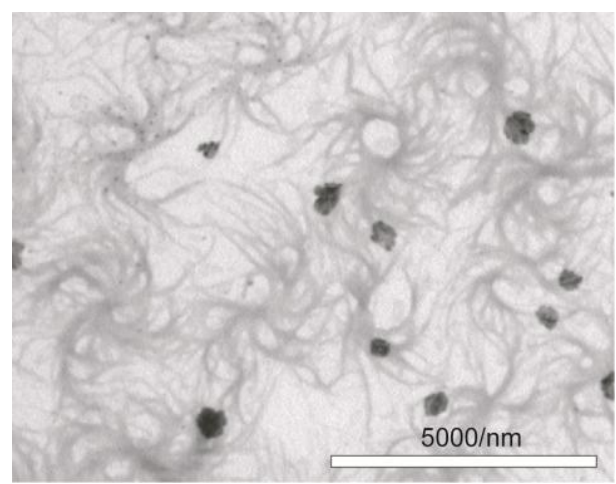

Fig. 4 TEM image of polymerization products from cross-linked EGII $_{\text {core2H }}$. 
crystallization induced by the concentrated active sites in the cross-linked EGII ${ }_{\text {core2H }}$, which does not bind to the crystalline cellulose because of lack of cellulose-binding domain. ${ }^{11 \mathrm{a}}$ Taken together, the polymerization should proceed extremely 5 fast and the insoluble part of synthetic cellulose with high molecular weight is produced at once as described above.

The morphology of synthesized cellulose was studied by TEM observation. In the present case, fibrous cellulose is formed (Fig. 4). The length of fibril is over $\mu \mathrm{m}$ length and its 10 width is in the range of $50-120 \mathrm{~nm}$. In our previous work, the synthetic cellulose by enzymatic polymerization yielded only plate-shape crystals. ${ }^{12 \mathrm{~b}}$ These different results seem to be the consequence of the different polymerizatoin processes. In the previous work utilizing mutant EGII as a catalyst, cellulose 15 was synthesized progressively, so that the crystal formation of synthetic cellulose seemed to proceed under thermodynamical control, resulting in formation of plate-shape crystals. On the other hand, the cross-linked $\mathrm{EGII}_{\text {core2H }}$ should generate multiple cellulose chains due to the dense active sites locally, 20 cellulose chains may be assembled under kinetical control, leading to fibrile formation. Therefore, the configuration of enzyme in vitro synthesis to cellulose seems to influence the morphology of synthetic cellulose as is the case of in vivo synthesis. However, in depth analysis for formation of fibrous 25 cellulose is now under way.

In summary, we prepared a cross-linked mutant endoglucanase II inspired from the natural cellulose synthase complex, and the effect of cross-linking of the enzymes on enzymatic polymerization was examined. The cross-linked 30 enzyme showed higher polymerization activity than noncross-linked enzyme due to the synergy effect of the local concentration of the enzymes. The morphology of synthetic cellulose catalyzed by the cross-linked mutant EGII was fibril. This result clearly indicates that the enzyme local arrangement 35 of in vitro synthesis has potential to regulate enzyme activity as well as the morphology of synthetic cellulose.

We thank Dr. K. Kuwata at Kyoto University for MALDITOF MS experiments.

\section{${ }_{40}$ Notes and references}

1 (a) D. Delmer and Y. Amor, Plant Cell, 1995, 7, 987; (b) D. Delmer, Annu. Rev. Plant Physiol. Plant Molecule. Biol., 1999, 50, 245; (c) M. Doblin, I. Kurek, D. Jacob-Wilk and D. Delmer, Plant Cell Physiol., 2002, 43, 1407.

452 (a) R. M. Brown and D. Montezinos, Proc. Natl. Acad. Sci. U. S. A., 1976, 73, 143; (b) R. M. Brown, J. H. M. Willison and C. L. Richardoson, Proc. Natl. Acad. Sci. U. S. A., 1976, 73, 4565; (c) W.R. Scheible, R. Eshed, T. Richmond, D. Delmer and C. Somerville, Proc. Natl. Acad. Sci. U. S. A., 2001, 98, 10079; (d) N. G. Taylor, R. M. Howells, A. K. Huttly, K. Vickers and S. R. Turner, Proc. Natl. Acad. Sci. U. S. A., 2003, 100, 1450

3 (a) W. Herth, Planta, 1983, 159, 347; (b) K. Okuda and S. Mizuta, Jpn. J. Phycol., 1993, 41, 151; (c) I. Tsekos, Protoplasma, 1996, 193, 10; (d) W.-R. Scheible, R. Eshed, T. Richmond, D. Delmer and C. Somerville, Proc. Natl. Acad. Sci. U. S. A., 2001, 98, 10079.

4 (a) S. C. Mueller and R. M. Brown, J. Cell Biol., 1980, 84, 315; (b) T Itoh, J. Cell Sci., 1990, 95, 309; (c) S. Kimura and T Itoh, Protoplasma, 1996, 194, 151

5 (a) E. A. Bayer, E. Setter and R. Lamed, J. Bacteriol., 1985, 163, 60552 ; (b) R. Lamed and E A. Bayer, Adv. Appl. Microbiol., 1988, 33,
1; (c) E. A. Bayer, J. P. Belaich, Y. Shoham and R. Lamed, Annu. Rev. Microbiol., 2004, 58, 521.

6 H. P. Fierobe, F. Mingardon, A. Mechaly, A. Belaich, M. T. Rincon, S. Pages, R. Lamed, C. Tardif, J. P. Belaich and E. A. Bayer, J. Biol. Chem., 2005, 280, 16325.

7 (a) T. H. Jr. Giddings, D. L. Brower, and L. A. Staehelin, J. Cell. Biol., 1980, 84, 327; (b) D. Delmer, Annu. Rev. Plant Physiol., 1987, 38, 259; (c) I. Tsekos and H-D. Reiss, Protoplasma, 1992, 169, 57; (d) I. Tsedos, J. Phycol., 1999, 35, 635.

708 (a) K. Okuda and R. M. Brown, Protoplasma, 1992, 168, 51; (b) M. Wada, J. Sugiyama and T. Okano, J. Appl. Polym. Sci., 1993, 49, 1491; (c) K. Okuda, I. Tsekos and R. M. Brown, Protoplasma, 1994, 180, 49; (d) S. Kimura and T. Itoh, Protoplasma, 1996, 194, 151; (e) M. Wada, T. Okano and J. Sugiyama, Cellulose, 1997, 4, 221; (d) I. Tsekos, J. Phycol., 1999, 35, 635; (f) T. Imai, J. Sugiyama, T. Itoh and F. Horii, J. Struct. Biol., 1999, 127, 248.

9 (a) S. Kobayashi, L. J. Hobson, J. Sakamoto, S. Kimura, J. Sugiyama, T. Imai and T. Itoh, Biomacromolecules, 2000, 1, 168; (b) M. Hiraishi, K. Igarashi, S. Kimura, M. Wada, M. Kitaoka and M. Samejima, Carbohydr. Res., 2009, 344, 2468.

10 (a) J. Y. Zhu, R. Sabo and X. Luo, Green. Chem., 2011, 13, 1339; (b) C. Cateto, G. Hu and A. Ragauskas, Energy Environ. Sci., 2011, 4, 1516.

11 (a) S. Kobayashi, K. Kashiwa, T. Kawasaki and S. Shoda, J. Am. Chem. Soc., 1991, 113, 3079; (b) S. Kobayashi, J. Sakamoto and S. Kimura, Prog. Polym. Sci., 2001, 26, 1525; (c) S. Kobayashi and A. Makino, Chem. Rev., 2009, 109, 5288

12 (a) I. Nakamura, H. Yoneda, T. Maeda, A. Makino, M. Ohrmae, J. Sugiyama, M. Ueda, S. Kobayashi and S. Kimura, Macromol. 90 Biosci., 2005, 5, 623; (b) I. Nakamura, A. Makino, J. Sugiyama, M. Ohrmae and S. Kimura, Int. J. Biol. Macromol., 2008, 43, 226; (c) I. Nakamura, Y. Horikawa, A. Makinon, J. Sugiyama and S. Kimura, Biomacromolecules, 2011, 12, 785.

13 (a) E. Hochuli, H. Dobeli and A. Schacher, J. Chromatogr., 1987, 95 411, 177; (b) D. Kroger, M. Liley, W. Schiweck, A. Skerra and H. Vogel, Biosens, Bioelectron., 1999, 14, 155; (c) A. Tinazli, J. L. Tang, R. Valiokas, S. Picuric, S. Lata, J. Piehler, B. Liedberg and R. Tempe, Chem. Eur. J., 2005, 11, 5249; (d) L. Chen, J. Kopecek and R. J. Stewartt, Bioconjugate Chem., 2000, 11, 734.

10014 A. Takeda, A. Hachimori, M. Murai, K. Sato and T. Samejima, J. Biochem., 1975, 78, 911.

15 S. Egusa, T. Kitaoka, M. Goto and H. Wariishi, Angew. Chem.-Int. Edit., 2007, 46, 2063. 